\title{
Determination of phytoplankton abundances (Chlorophyll-a) in the optically complex inland water - the Baltic Sea
}

\author{
Daoxi Zhang ${ }^{\mathrm{a}, \mathrm{b}, *}$, Samantha Lavender ${ }^{\mathrm{c}, \mathrm{d}}$, Jan-Peter Muller ${ }^{\mathrm{b}}$, David Walton ${ }^{\mathrm{b}}$, \\ Bengt Karlson ${ }^{\mathrm{e}}$, Johan Kronsell \\ ${ }^{a}$ Institute of Hydroecology, Ministry of Water Resources and Chinese Academy of Sciences, \\ Wuhan, China \\ ${ }^{b}$ Mullard Space Science Laboratory, Department of Space and Climate Physics, \\ University College London, Holmbury St. Mary, Dorking, UK \\ ${ }^{c}$ Pixalytics Ltd, Plymouth Science Park, 1 Davy Road, Plymouth, UK \\ ${ }^{d}$ School of Marine Science and Engineering, \\ University of Plymouth, Drake Circus, Plymouth, UK \\ ${ }^{e}$ Swedish Meteorological and Hydrological Institute, Oceanographic unit, \\ Sven Källfelts gata 15, SE-426 71 Västra Frölunda, Sweden
}

\begin{abstract}
A novel approach, termed Summed Positive Peaks (SPP), is proposed for determining phytoplankton abundances (Chlorophyll-a, Chl-a) and surface phytoplankton bloom extent in the optically complex Baltic Sea. The SPP approach is established on the basis of a baseline subtraction method using Rayleigh corrected top-of-atmosphere data from the Medium Resolution Imaging Spectrometer (MERIS) measurements. It calculates the reflectance differences between phytoplankton related signals observed in the MERIS red and near infrared (NIR) bands, such as sun-induced chlorophyll fluorescence (SICF) and the backscattering at $709 \mathrm{~nm}$, and considers the summation of the positive line heights for estimating Chl-a concentrations. The SPP algorithm is calibrated against near coincident in situ data collected from three types of phytoplankton dominant waters encountered in the Baltic Sea during $2010(\mathrm{~N}=379)$. The validation results show that the algorithm is capable of retrieving Chl-a con-
\end{abstract}

\footnotetext{
* Corresponding author.

Email address: dxzhang@mail.ihe.ac.cn (Daoxi Zhang)
} 
centrations ranging from 0.5 to $3 \mathrm{mg} \mathrm{m}^{-3}$, with an RMSE of $0.24 \mathrm{mg} \mathrm{m}^{-3}$ $\left(\mathrm{R}^{2}=0.69, \mathrm{~N}=264\right)$. Additionally, the comparison results with several Chl-a algorithms demonstrates the robustness of the SPP approach and its sensitivity to low to medium biomass waters. Based on the red and NIR reflectance features, a flagging method is also proposed to distinguish intensive surface phytoplankton blooms from the background water.

Keywords: Satellite remote sensing, Phytoplankton abundance, Chlorophyll-a, MERIS, Baltic Sea

\section{Introduction}

Being an optically active constituent present in natural waters, phytoplankton play a significant role in aquatic ecosystems. They provide organic compounds for aquatic organisms to sustain food webs and maintain essential ecological functions (Falkowski \& Raven, 2013). In coastal and inland waters, on the other hand, the role of phytoplankton can be associated with the adverse effects of surface blooms that taint water resources, disrupt recreation and tourism activities. As one of the largest brackish water bodies located in the northern Europe, the Baltic Sea is known to have annual occurrence of summer phytoplankton blooms. Over the last few decades, the extensive nuisance algal blooms with a surface coverage of up to $100,000 \mathrm{~km}^{2}$ have been more frequently observed in this region (Kahru et al., 2007).

Satellite remote sensing has been shown to be one of the most effective means to derive phytoplankton information from various water bodies (Kutser, 2004; Martin, 2004; Kahru et al., 2007; Stumpf et al., 2008; Hu et al., 2010; Hunter et al., 2010). It provides synoptic views, with spatially and temporally cohesive coverage of global waters from open oceans to inland lakes at a near daily frequency. Chlorophyll-a (Chl-a), acting as the primary photosynthetic pigment of phytoplankton, has been widely used as a proxy to indicate phytoplankton 
abundances (Vos et al., 2003; Gons et al., 2008; Ruiz-Verdu et al., 2008; Nair et al., 2008; Moses et al., 2009; Brewin et al., 2013; Al-Naimi et al., 2017). To derive phytoplankton abundances in productive inland and coastal waters through Chl-a concentrations, the recently developed bio-optical algorithms are primarily focused on the use of the spectral features observed in the red and NIR regions (Gons, 2005; Dall'Olmo \& Gitelson, 2005; Duan et al., 2010; Le et al., 2013; Kutser et al., 2016). A number of studies have demonstrated their performances and applicability to ocean colour data (Dall'Olmo \& Gitelson, 2006; Gons et al., 2008; Moses et al., 2012). Yet these studies were either based on in situ radiometric observations or subject to atmospheric correction procedures.

Another type of approach developed for estimating Chl-a concentrations and bloom distributions is ocean colour indices. These indices were established on the basis of baseline subtraction methods, and are characterised by the calculation of the reflectance peak heights at a few Chl-a related red and NIR signals measured at the top-of-atmosphere (TOA). Because of the simplicity and the lack of needs for fully atmospheric corrected spectral data, ocean colour indices, such as Fluorescence Line Height (FLH, Gower et al. 1999), Maximum Chlorophyll Index (MCI, Gower et al. 2005), Floating Algae Index (FAI, Hu 2009) and Maximum Peak Height(MPH, Matthews et al. 2012) have been widely used. During bloom seasons, however, phytoplankton biomass varies significantly in time, location and scale. Only considering the spectral variation observed in a single band, such as SICF or particulate backscattering, the derived index may not be sufficient to reveal all over changes in phytoplankton abundances within the water considered (Hu et al., 2012). This especially true for the case in the Baltic Sea, where the surface phytoplankton species composition shifts from eukaryotes to cyanobacteria through summer. A number of studies have 
demonstrated that the index derived from the FLH approach has a great potential to retrieve Chl-a concentrations from low-medium biomass waters (Gower et al., 1999; Gower \& King, 2007; Gons et al., 2008; Palmer et al., 2014; Hu \& Feng, 2017), and the magnitudes of NIR reflectance peak heights are more suitable for determining phytoplankton abundances and bloom distributions in high biomass waters (Gower et al., 2006, 2008; Alikas et al., 2010; Hu et al., 2010; Binding et al., 2011; Palmer et al., 2014; Qi et al., 2015). In order to obtain all over information on phytoplankton community, it is necessary to simultaneously consider all Chl-a related reflectance features measured within the red and NIR bands.

Being a heritage satellite sensor, Medium Resolution Imaging Spectrometer (MERIS) had been providing higher spectral ocean colour data over the first decade of the 21st century. The continued exploitation of the MERIS data archive will significantly informs the algorithm development and allows new applications for the Sentinel-3 Ocean and Land Colour Instrument (OLCI) launched in February 2016.

In this paper, we present a new approach for determining phytoplankton abundance or Chl-a in the optically complex Baltic Sea using MERIS Rayleigh corrected surface reflectance or Bottom of Rayleigh Reflectance (BRR). The proposed algorithm, named the Summed Positive Peaks (SPP), calculates the magnitudes of three Chl-a related MERIS TOA signals, and considers the summation of the positive line heights to define the SPP variables. The objectives here are to (1) evaluate the accuracy of the established SPP algorithm and its performance under various environmental conditions over the study site; (2) assess the reliability of standard satellite Chl-a products in comparison with the SPP Chl-a estimates; (3) discuss the advantages and limitations of the SPP approach in estimating phytoplankton abundances in the Baltic Sea. 


\section{Data and methods}

75 2.1. Description of study area

Covering a surface area of $\sim 410,000 \mathrm{~km}^{2}$, and with an average depth of 52 m (Wasmund \& Uhlig, 2003), the Baltic Sea is one of the largest semi-enclosed shallow brackish inland seas in Europe. It consists of several major sub-basins including the Gulf of Bothnia, Gulf of Finland, Gulf of Riga, Baltic Proper and Kattegat (see Figure 1) that are separated by shallow sills. The extensive catchment, with an area of over $1,700,000 \mathrm{~km}^{2}$, is comprised of nine surrounding coastal countries (HELCOM, 2003, 2006). Compared with open ocean waters, the restricted saline water inflow from the North Sea has made the salinity of the Baltic Sea relatively low (Kratzer et al., 2008). Generally, the salinity level is characterised by a horizontal gradient with the higher values observed in the southwest Danish straits decreasing towards the northernmost region in the Bothnian Bay. In addition, the salinity also exhibits a vertical gradient with the lowest values in the surface layer.

This vertical stratification is associated with the formation of a halocline that isolates the surface water from the dense deep waters, and restricts vertical mixing of the water column. With respect to the vertical temperature stratification, the thermocline develops in spring and becomes prevalent at a depth of between $15 \mathrm{~m}$ and $20 \mathrm{~m}$ in most Baltic basins during the summer (Reissmann et al., 2009). Substantial nutrients, organic and inorganic substances together with suspended sediments have been retained in its coastal lagoons (e.g. Vistula and the Curonian Lagoon), the Gulf of Riga and Gulf of Finland. These substantial nutrient concentration have led the coastal regions of the Sea becoming eutrophicated (HELCOM, 2003; UNECE, 2007). The transition of organic materials and suspended sediments from the coastal areas to the central region has also resulted in the entire sea being optically dominated by CDOM (Kowalczuk 


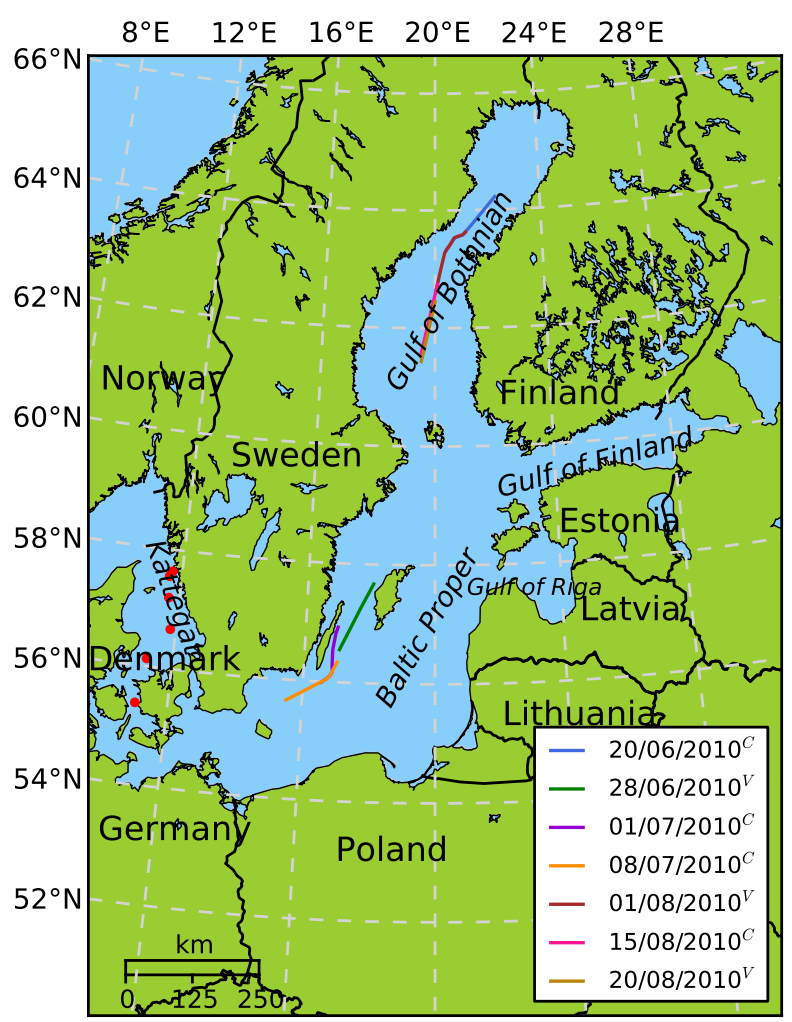

Figure 1: Baltic Sea map showing the locations of the near-concurrent in situ data used in this study. The colourised lines show the ship transects of in situ observations where nearconcurrent satellite images are available. The red filled dots show the locations of the reference stations where water samples were collected for the in situ data validation. The legend shows the dates of in situ measurements, and in situ data used for the algorithm calibration and validation are indicated with $\mathrm{C}$ and $\mathrm{V}$ in superscripts, respectively.

et al., 2005, 2006).

In terms of phytoplankton communities, annually occurring algal blooms are observable in both spring and summer seasons. In particular, the spring blooms usually start in the southern Baltic Sea during early March, progress through the central part of the sea in April and then reach the Gulf of Finland during May. The composition of the spring bloom assemblages includes large-celled diatoms such as Thalassiosira levanderi and chain-forming single-celled, and sometimes toxin-producing, dinoflagellates such as Peridiniella catenata and 
Dinophysis acuminata (Wasmund et al., 1998; Hällfors et al., 2011). During the summer months, when persistent solar irradiance and little wind mixing are present, cyanobacteria dominate the phytoplankton assemblages and form dense surface accumulations. The proliferation of cyanobacteria usually starts in the Baltic Proper in early summer and extends into the Gulf of Finland by the end of August. Compared with spring blooms, summer phytoplankton blooms primarily consist of toxic Nodularia spumigena, Dolichospermum spp. and Aphanizomenon flos-aquae (Sellner, 1997), and the biomass is generally low with a Chl-a concentration of less than $2 \mathrm{mg} \mathrm{m}^{-3}$ typically observed in the Bothnian Bay and Kattegat. An increased biomass is measurable in the Bothnian Sea, Baltic Proper and Gulf of Finland; whereas higher concentrations of more than $20 \mathrm{mg} \mathrm{m}^{-3}$ are common in the coastal lagoons of Vistula and Oder (Håkanson \& Bryhn, 2008). With respect to a subsurface chlorophyll maximum, this is normally observed in the Kattegat and the Skagerrak (Karlson et al., 1996).

\subsection{In situ data}

The in situ dataset was collected using an automated flow-through system by the Swedish Meteorological and Hydrological Institute (SMHI) during its routine water quality monitoring programme. A series of physical and biochemical variables, including water temperature and salinity, were measured along the pre-defined pathway between Kattegat and the Bothnian Bay at a depth of 3 m. Meanwhile, the geo-locations of in situ measurements were recorded by a Global Positioning System (GPS) onboard the research ferry at a frequency of 20 seconds that provides a traverse sampling resolution of $\sim 200 \mathrm{~m}$. In situ Chl-a fluorescence was measured simultaneously with water turbidity by the integrated fluorometer and turbidity sensor (ECO FLNTU, WET Labs, Inc.).

To control the quality of the collected datasets, only when all variables at 
a sampling point were within the acceptable range, the measurements were considered valid. For instance, if the difference between the water temperature measured at the inlet and inside of the system was larger than $1^{\circ} \mathrm{C}$, then, an inappropriate water flow was considered to pass through the system and all other variables recorded at this time are excluded.

To calibrate the Chl-a concentrations measured in situ, an automated sampler $(6712 \mathrm{FR}, \mathrm{ISCO}$, Inc.) pre-configured with the geo-locations of 6 reference stations between Lübeck (Germany) and Gothenburg (Sweden) (see Figure 1) was carried onboard to collect water samples every two weeks when the flowthrough system was in operation. The collected water samples were kept refrigerated, at a fixed temperature of $4{ }^{\circ} \mathrm{C}$ in a dark environment, before being transferred to the laboratory. They were then filtered through Whatman GF/F filters, then the pigment extraction was performed immediately using 96\% ethanol (Arvola, 1981) in a subdued light environment. After the extraction, Chl-a fluorescence of each water sample was determined through a fluorescence spectrophotometer (Hitachi F-2500, Inc.) at excitation and emission wavelengths of $430 \mathrm{~nm}$ and $665 \mathrm{~nm}$, respectively. The measured fluorescence was then converted to Chl-a concentrations using the following equation:

$$
\text { [Chl-a] }\left(m g m^{-3}\right)=R \times f \times s \times e \times V^{-1}
$$

where $R$ is the fluorescence intensity from the direct fluorometer reading; $f$ is the calibration factor determined using certified reference material, see (HELCOM, 2005); $s$ is the slit factor, from the slit width settings of the instrument; $e$ is the volume of ethanol used for the pigment extraction, in a unit of $\mathrm{cm}^{3} ; V$ is the volume of filtered sample water, in litres.

Then, the obtained Chl-a data were used to calibrate the in situ measured Chl-a concentrations. Note that water samples were only collected between 
Lübeck and Gothenburg to minimise the Chl-a pigment degradation. The calibration of the Ferrybox system is performed at the Finnish Environment Institute (SYKE) on an annual basis, with a culture of microalgae Monoraphidium contortum used to create a set of standardised Chl-a concentrations.

\subsection{Satellite data}

The 3rd re-processed collection of Reduced Resolution (RR) MERIS imagery is used in this paper. The datasets were acquired from the European Space Agency Earthnet FTP site (ftp://eoa-up.eo.esa.int), and processed with the Basic ENVISAT AATSR and MERIS (BEAM Ver. 4.10.3.) Toolbox. The L1b Radiometry Processor (Ver. 1.1.1) was first applied to the RR L1b datasets for the radiometric recalibration and for the "smile" effect and the detector-todetector systematic radiometric difference corrections. Then, the Cloud Probability Processor (Ver. 1.5.203) was used to produce a cloud probability product. To minimise potential errors related to the atmospheric correction, only atmospheric effects of gaseous absorption, ozone and molecular Rayleigh scattering were removed using the bottom-of-Rayleigh reflectance processor (Ver.2.3). The output reflectance product, known as the Rayleigh corrected surface reflectance or Bottom of Rayleigh Reflectance (BRR), can be described as follows:

$$
\rho_{B R R}=\rho_{T O A}^{*}-\rho_{R}
$$

where $\rho_{T O A}^{*}$ is the top-of-atmosphere (TOA) reflectance after removing ozone and gaseous absorption effects, and $\rho_{R}$ is the reflectance from the Rayleigh scattering. $\rho_{R}$ was calculated using the $6 \mathrm{~S}$ radiative transfer code (Vermote et al., 1997) within the bottom-of-Rayleigh reflectance processor.

To evaluate the performance of the proposed method in retrieving Chl-a 
concentrations, the MERIS C2R_Chl-a product generated by the MERIS Case2 Regional processor (C2R, Ver. 1.5.8) (Doerffer \& Schiller, 2008) alongside the standard MERIS Level 2 (L2) Algal-2 product from the Earthnet FTP site are used for this investigation. In addition, MODIS-Aqua datasets, provided by the U.S. NASA Goddard Space Flight Center (GSFC) (http://oceancolor . gsfc.nasa.gov/), are also included. The datasets were processed with the default atmospheric correction algorithm (2-band model selection and iterative NIR correction) in the SeaWiFS Data Analysis System (SeaDAS, version 6.4) to generate the MODIS Ocean Colour 4 (OC4) Chl-a product. The invalid Chl-a retrievals and no data pixels within the above three satellite products are excluded based on the indication of 'invalid' flag within each product. Table 1 lists the satellite datasets used in this study.

Table 1: Description of the satellite datasets used in this study.

\begin{tabular}{cccc}
\hline Data Name & Data Type & Application & Source \\
\hline BRR & TOA reflectance & calibration and validation & BEAM, BRR processor \\
MERIS C2R Chl-a & Chl-a product & algorithm evaluation & BEAM, C2R processor \\
MERIS Algal-2 & Chl-a product & algorithm evaluation & ESA Earthnet \\
MODIS OC4 & Chl-a product & algorithm evaluation & SeaDAS, GSFC \\
\hline
\end{tabular}

\subsubsection{Match-up data selection}

During the match-up data selection procedure, the cloud masks from the cloud probability product together with the L1b 'bright' pixel available in the Rayleigh corrected surface reflectance datasets were used to exclude cloud pixels. To minimise the mismatch of the sampling time between satellite and in situ measurements, a strict time window of \pm 2 hours (Bailey \& Werdell, 2006) was used for the satellite pixel extraction. Additionally, to minimise the error associated with satellite sensor noise, a $3 \times 3$ median filter was applied, where 
only the satellite pixels $(1.2 \mathrm{~km} \times 1.2 \mathrm{~km})$ containing more than three in situ records were considered and used for the algorithm development; otherwise, the satellite pixels were discarded (Hu et al., 2001). Under these strict criteria, only seven of the datasets were matched up. These datasets were collected during the summer 2010, covering an area from the south west to the north east of the Baltic Sea with in situ Chl-a concentrations spanning a range from 0.5 to $4 \mathrm{mg}$ $\mathrm{m}^{-3}$, see Figure 1 for the location of the ship transects of the in situ observations used for the algorithm calibration and validation. In particular, to calibrate the algorithm, four match-up datasets were used, two of which were collected from the Gulf of Bothnia and the other two match-ups from the Baltic Proper. The remaining three match-ups, collected from the central and northern parts of the sea, were used for the algorithm validation.

\section{Algorithm Development}

\subsection{Observed Rayleigh corrected surface reflectance}

Figure 2 shows the Rayleigh corrected surface reflectances observed over the Baltic Sea. In particular, the reflectance spectra in Panel A show noticeable peaks of chlorophyll fluorescence at $681 \mathrm{~nm}$, whereas troughs are readily observable at the same wavelength in Panel C and D. Panel B contains reflectance spectra that have less distinct fluorescence peaks and observable reflectance peaks at $709 \mathrm{~nm}$, with the reflectance line heights calculated using MERIS bands 8 and 9 both being positive. Panel $\mathrm{C}$ shows the case where the $709 \mathrm{~nm}$ reflectance overwhelms the $681 \mathrm{~nm} \mathrm{SICF}$, and the positive line height is only obtainable from MERIS band 9. The reflectance spectra shown in Panel D possess terrestrial vegetation-like reflectance shapes that are characterised by strong reflectance signals in the NIR region, and have marked reflectance peaks at $754 \mathrm{~nm}$ (MERIS band 10). In this case, two positive reflectance line heights 

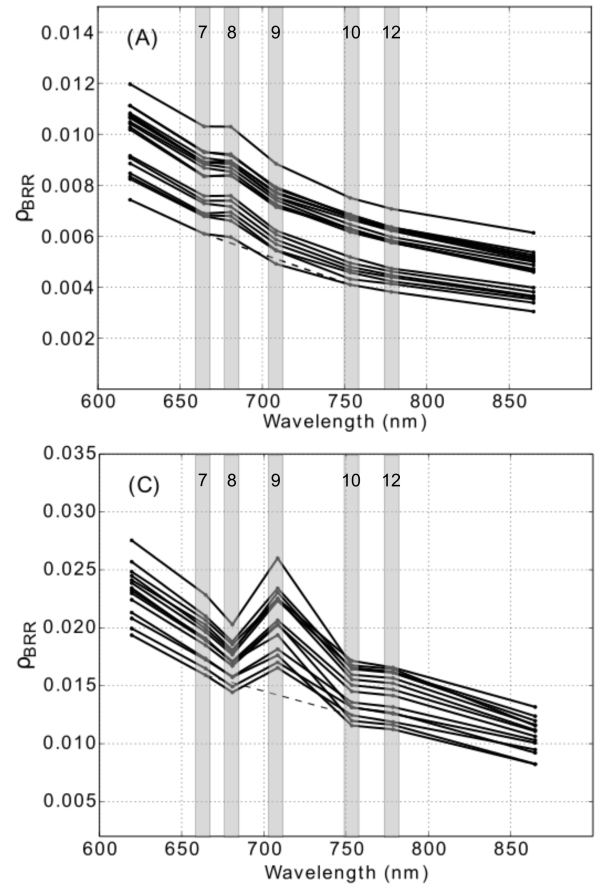
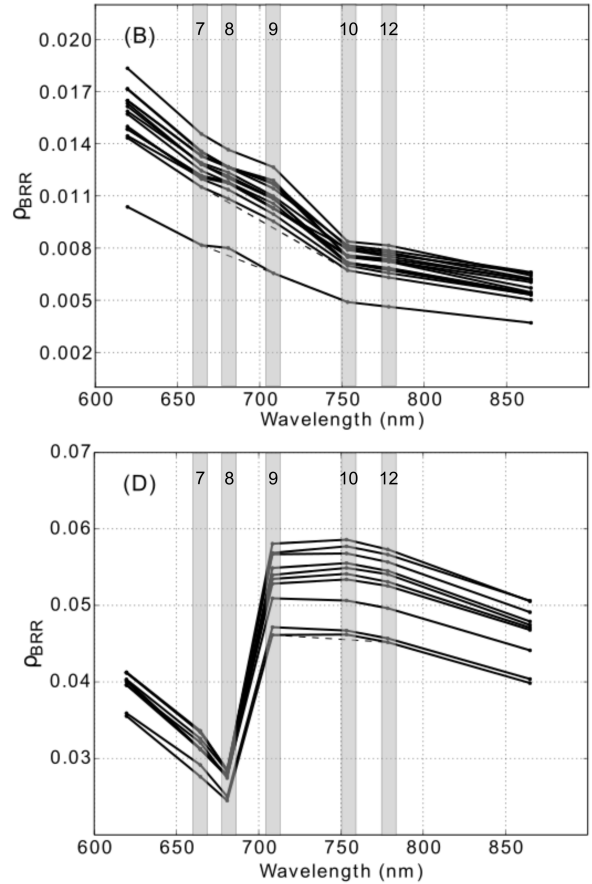

Figure 2: Rayleigh corrected surface reflectance for four different water types encountered in the Baltic Sea. The filled black dots on each spectrum are the positions of MERIS bands $6,7,8,9,10,12$ and 13 centred at $620,664,681,709,754,779$ and $865 \mathrm{~nm}$, respectively. (A) represents the reflectance spectra of eukaryote dominated waters, where the peak of the sun-induced chlorophyll fluorescence is observable in MERIS band 8 at $681 \mathrm{~nm}$; (B) shows the reflectance spectra of water that has an increased biomass in the surface layer; (C) presents the spectral reflectances where surface accumulations occur, with a distinct reflectance peak at $709 \mathrm{~nm}$; (D) shows the reflectances that possess land vegetation-like spectral shapes and have the marked reflectance signal at $754 \mathrm{~nm}$. The dotted lines on each panel show two baselines used by the SPP algorithm.

The presence of the Chl-a fluorescence peak at $681 \mathrm{~nm}$ is usually related to sufficient phytoplankton biomass (Gower et al., 1999; Gower \& King, 2007), and the emergence of the $709 \mathrm{~nm}$ reflectance peak is known from the increased Chl-a concentrations of phytoplankton assemblages comprised of either eukaryotes or cyanobacteria (Gower et al., 2003; Ruiz-Verdu et al., 2008). However, in the case where eukaryotes and cyanobacteria coexist, the $709 \mathrm{~nm}$ peak is unlikely to 
result from the eukaryotes, as most cyanobacteria species have competitive advantages over eukaryotic phytoplankton during summertime (Paerl \& Huisman, 2009).

\subsection{The Summed Positive Peaks algorithm}

Based on the reflectance spectra observed over the Baltic Sea and the changing species composition of phytoplankton assemblages during the growing seasons, a modified baseline subtraction algorithm termed the Summed Positive Peak height (SPP) algorithm is proposed. This algorithm has a similar form to other baseline approaches established for detecting phytoplankton blooms, such as FLH (Gower et al., 1999), MCI (Gower et al., 2005) and FAI (Hu, 2009). Instead of measuring a single line height at a fixed wavelength, the SPP approach considers three Chl-a related reflectance features in MERIS bands 8, 9 and $10(681,709$ and $754 \mathrm{~nm})$ simultaneously. It calculates the line heights for the $681 \mathrm{~nm}$ SICF and $709 \mathrm{~nm}$ particulate backscattering and sums the positive magnitudes to define the SPP variables. To avoid artifacts that might appear in band 10 when the variable is derived from low biomass waters, separate baselines are utilised during the algorithm development process. The mathematical definition of the SPP algorithm can be described using the following equations:

$$
S P P=\sum_{i=1}^{3} \operatorname{Peak}_{i}\left(\lambda_{i}\right), \text { if } \operatorname{Peak}_{i}>0
$$

$$
\operatorname{Peak}_{1,2}\left(\lambda_{1,2}\right)=\rho_{B R R, \lambda_{1,2}}-\rho_{B R R, 664}-\left(\left(\rho_{B R R, 754}-\rho_{B R R, 664}\right) *\left(\lambda_{1,2}-664\right) /(754-664)\right)
$$

$$
\operatorname{Peak}_{3}\left(\lambda_{3}\right)=\rho_{B R R, \lambda_{3}}-\rho_{B R R, 709}-\left(\left(\rho_{B R R, 779}-\rho_{B R R, 709}\right) *\left(\lambda_{3}-709\right) /(779-709)\right)
$$

where $\lambda_{i}$ is the wavelength of MERIS bands at 681,709 and $754 \mathrm{~nm}$, respectively. 
The succession of species dominance in phytoplankton assemblages from early to late summers in the Baltic Sea can be generally separated into three stages:

1. In early summer, before the thermocline develops and the water column is well mixed, eukaryotic species such as diatoms and dinoflagellates are homogeneous distributed in the upper layer with low to medium cyanobacteria biomass;

2. When the thermocline develops and the water column is gradually separated, cyanobacteria start growing and gradually become abundant in the surface layer;

3. When the thermocline is well developed in late summer, high biomass cyanobacteria-dominated phytoplankton assemblages are prevalent in the surface water;

4. When solar irradiance and calm weather conditions persist for a few days (or weeks), surface scums appear at the water surface.

The variation of species dominance in the surface layer phytoplankton assemblages alters the MERIS reflectance shapes. For each stage, it can be considered separately.

\subsubsection{Eukaryote dominant waters}

Prior to cyanobacteria assemblages becoming abundant in the surface layer, eukaryotes make up most of the total phytoplankton biomass and coexist with cyanobacteria in the upper layer (Stal et al., 2003). Under this condition, the Chl-a concentration in the surface water is relatively low (generally less than 2 $\mathrm{mg} \mathrm{m} \mathrm{m}^{-3}$ in the Baltic Sea), and SICF produced by the eukaryotic phytoplankton 
is readily detectable. To utilise SICF for retrieving chlorophyll from phytoplankton assemblages, a baseline subtraction approach measuring the $681 \mathrm{~nm}$ peak height of the SICF has been established. A number of studies have investigated the relationship between measured FLH and Chl-a concentrations (Hoge et al., 2003; Hu et al., 2005), and the impacts of non-algal materials and CDOM on the observed water-leaving SICF signal (McKee et al., 2007). Validation studies have further demonstrated the significant potential of using FLH for deriving Chl-a concentrations from phytoplankton dominated inland and coastal waters (Gower et al., 1999; Gower \& King, 2007; Gons et al., 2008; Palmer et al., 2014). In this case, the SPP approach calculates the line height of the $681 \mathrm{~nm}$ SICF peak above the baseline.

\subsubsection{Eukaryotes and cyanobacteria coexist in phytoplankton assemblages in the surface mixed layer}

The second stage is that cyanobacteria start growing and their biomass gradually becomes abundant within phytoplankton assemblages in the surface mixed layer. During this period, slightly decreased eukaryote biomass together with increased dominance of cyanobacteria typically account for a total Chl-a concentration of $2-4 \mathrm{mg} \mathrm{m}^{-3}$. The enhanced cyanobacteria biomass in the surface mixed layer enlarges the backscattering between 700 and $705 \mathrm{~nm}$ rather than elevating the SICF signal at $681 \mathrm{~nm}$ (Metsamaa et al., 2006). This enhanced reflectance causes the $709 \mathrm{~nm}$ reflectance peak to emerge. This is the case in the Baltic Sea where cyanobacteria gradually dominate phytoplankton assemblages in early and middle summer. Despite the fact that the MERIS sensor does not have the band configuration between 700 and $705 \mathrm{~nm}$, the signal measured in the band $9(709 \mathrm{~nm})$ is still able to provide sufficient information for Chl-a retrievals. For example, a number of red to NIR band ratio algorithms have been developed to estimate Chl-a concentrations in inland and coastal waters 
(Dall'Olmo \& Gitelson, 2005; Gons et al., 2008; Gitelson et al., 2009; Moses et al., 2009; Gilerson et al., 2010; Moses et al., 2012). For the mixed eukaryote and cyanobacteria water, the SPP approach summates the positive line heights of the $681 \mathrm{~nm}$ reflectance and 709 backscattering to account for the decreased eukaryotes and increased cyanobacteria.

\subsubsection{Cyanobacteria are dominant in the surface mixed layer}

When optimal weather conditions of persistent irradiance and little wind mixing appear, the subsurface cyanobacteria-dominated phytoplankton assemblages tend to float up towards the water surface to optimise their photosynthetic needs, and consequently form dense surface aggregations. The occurrence of surface cyanobacterial accumulations leads to the reflectance troughs and peaks at $681 \mathrm{~nm}$ and $709 \mathrm{~nm}$, respectively.

In high biomass phytoplankton dominated waters, the $709 \mathrm{~nm}$ peak height has been suggested as having a significant correlation with Chl-a concentration (Yacobi et al., 1995; Gitelson, 1992). Validation studies on inland lakes and coastal waters have further confirmed the potential of using the $709 \mathrm{~nm}$ reflectance for retrieving Chl-a concentrations from surface phytoplankton blooms (Gower et al., 2006, 2008; Alikas et al., 2010; Binding et al., 2011; Palmer et al., 2014; Qi et al., 2015). In this case, the SPP approach resembles the form of MCI, calculating the peak height of the $709 \mathrm{~nm}$ reflectance for estimating Chl-a concentrations.

When the optimal weather conditions persist for several days, or weeks, some of the surface blooms can further develop as surface scums. The appearance of surface scums is thought to be the effect of photoinhibition, photo-oxidation and dehydration that causes physical damage to cyanobacteria cells and results in the loss of buoyancy regulation (Abeliovich \& Shilo, 1972; Zohary \& Madeira, 1990). Assessing Chl-a concentrations for the water that contains cyanobacte- 
rial surface scums is difficult. The surface scums restrict the light availability in the water column and make the optical properties beneath the scum areas undetectable by satellite sensors. Quantitatively estimating Chl-a for the surface scums themselves is also not a trivial task (Kutser, 2004; Reinart \& Kutser, 2006; Hu et al., 2010). Optical properties of surface scums or dry floating algae resemble land vegetation, and Chl-a may vary with the health status as well as the age of cyanobacteria species. In addition, excessive heating and photo-oxidation can cause pigment decomposition, resulting in pigment bleaching (Sellner, 1997). Although an attempt was made to derive Chl-a from the surface scums (Kutser, 2004), using a bio-optical model, the result showed that the detailed bio-optical properties are needed for the further quantitative estimation. Therefore, the floating algae index (FAI) was proposed by $\mathrm{Hu}$ (2009) for deriving the spatial distribution. It calculates the peak height of the $859 \mathrm{~nm}$ reflectance observed in a MODIS land-band, and application examples have been demonstrated for detecting surface cyanobacteria scums in Lake Taihu, China (Hu et al., 2010). However, in temperate coastal waters such as the Baltic Sea, the occurrence of surface scums may not be as frequent as in hypertrophic lakes, which makes the distinct reflectance peak undetectable in the region beyond 800 $\mathrm{nm}$. Therefore, the line height of the $754 \mathrm{~nm}$ reflectance is calculated for distinguishing cyanobacteria-dominated phytoplankton assemblages alongside surface scums from the background water, and is described in the following section.

\subsection{A flag for cyanobacteria dominant waters}

By considering the sign of the measured SICF line heights, and comparing the reflectance difference between MERIS bands 9 and 10 at wavelengths of 709 and $754 \mathrm{~nm}$ respectively, a CyanoBloom_flag is proposed to distinguish cyanobacteria dominated waters (i.e. surface blooms and surface scums) from the background water. This flag can be defined as follows: 
CyanoBloom_flag $= \begin{cases}2, & \text { if } \rho_{B R R, 865}<\rho_{B R R, 754}, \text { Peak } 1<0, \rho_{B R R, 754}>\rho_{B R R, 709} \\ 1, & \text { if } \rho_{B R R, 865}<\rho_{B R R, 754}, \text { Peak } k_{1}<0, \rho_{B R R, 754}<\rho_{B R R, 709} \\ 0, & \text { if } \rho_{B R R, 865}>\rho_{B R R, 754}, \quad \text { (mask_out_as_land); }\end{cases}$

where $P e a k_{1}$ is the SICF peak height calculated using Equation 4. $\rho_{B R R, 681}$, $\rho_{B R R, 754}, \rho_{B R R, 865}$ are Rayleigh corrected surface reflectances measured at wavelengths of 681,754 and $865 \mathrm{~nm}$. $\rho_{B R R, 754}, \rho_{B R R, 865}$ are used to exclude land pixels when the reflectance difference is positive.

Based on the observed reflectance spectra over the Baltic Sea, see Figure 2, eukaryote dominant waters can be distinguished from cyanobacteria dominant waters using the observed $681 \mathrm{~nm}$ reflectance trough (Wynne et al., 2008). In particular, when cyanobacteria-dominated phytoplankton assemblages prevail in the surface mixed layer, strong backcattering overcomes water absorption and produces a distint reflectance peak discernible in MERIS band 9 (709 nm), see Panel C in Figure 2; As surface blooms develop, the $709 \mathrm{~nm}$ reflectance peak shifts toward the longer wavelength, and consquently produces the distinct reflectance peak (terrestrial-type spectral reflectance) readily observable in MERIS 10 when surface scums appear, see Panel D in Figure 2; and for both cases, the reflectance trough is presented in MERIS band 8 .

Finally, to associate the derived SPP variables with Chl-a concentrations, three models were tested: a linear model of $y=a+b x$; an exponential function of $y=a \exp (b x)$; and a power-law function $y=(a+b x)^{c}$. The function that has the highest correlation coefficient (R) is used for tuning the coefficients of the SPP algorithm. The root mean square error (RMSE) was used to judge the goodness of fit, and the mean absolute percentage error (MAPE) was calculated 
to estimate the systematic errors, the mathematical equations are as follows:

$$
\begin{gathered}
R M S E=\sqrt{\frac{\sum_{i=1}^{N}\left(Y_{i}-\hat{Y}_{i}\right)^{2}}{N}} \\
M A P E=\frac{1}{N} \sum_{i=1}^{N}\left|\frac{Y_{i}-\hat{Y}_{i}}{Y_{i}}\right| * 100
\end{gathered}
$$

Where $\mathrm{N}$ is the number of observations, $\mathrm{Y}$ is the observed value and $\hat{Y}$ is the predicted value.

\subsection{Algorithm calibration and validation}

In order to obtain a single algorithm for estimating Chl-a concentrations in the Baltic Sea, four match-up datasets are chosen for the algorithm calibration.

The criteria applied to the selection of calibration match-up datasets are as follows:

1. In situ observations should cover as much of the Baltic Sea as possible;

2. In situ measurements should span as long a time period as possible;

3. In situ data should cover as wide a range of Chl-a concentrations as possible;

4. Area surrounding in situ measurements should contain as little cloud coverage as possible.

Based on these criteria, four match-up datasets collected on 20th June, 1st July, 8th July and 15th August 2010 were selected. In the algorithm calibration procedure, the SPP variables are regressed against the near-concurrent in situ Chl-a using a non-linear power-law model $y=(a+b x)^{c}$ that gave the highest correlation values, with the best fit given in Panel A Figure 3 with Equation 9 showing the calibration result. 

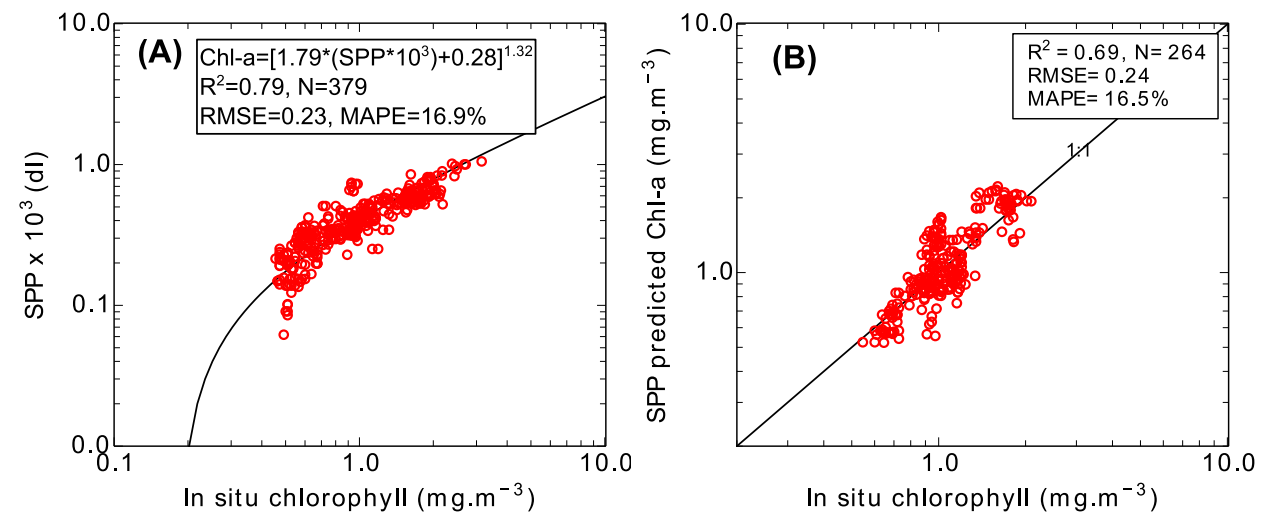

Figure 3: Scatter plots showing the calibration and validation results of the SPP algorithm. Panel A shows the SPP variable versus in situ chlorophyll. Panel B shows the SPP chlorophyll concentrations versus Chl-a measured in situ.

$$
\text { Chl-a } \left.=\left[1.79 \times\left(S P P * 10^{3}\right)+0.28\right)^{1.32}\right]
$$

The calibration result shows that the coefficient of determination $\left(R^{2}\right)$ is equal to 0.79 and RMSE is $0.23 \mathrm{mg} \cdot \mathrm{m}^{-3}$ (MAPE $=16.9 \%, \mathrm{p}=0.00, \mathrm{~N}=379$ ) for a Chl-a range from 0.5 to $4 \mathrm{mg} \cdot \mathrm{m}^{-3}$, indicating that $79 \%$ of the variance within the in situ data is explained by the SPP variables with a minimum Chl-a concentration of $0.19 \mathrm{mg} \cdot \mathrm{m}^{-3}$ detectable.

To assess the accuracy of the calibrated equation, the remaining match-up datasets collected on 28th June, 1st August and 20 August 2010 were used (see Figure 1 for the ship transects). The result is shown in Panel B Figure 3. In particular, for the water where Chl-a ranges from 0.5 to $3 \mathrm{mg} \cdot \mathrm{m}^{-3}, 69 \%$ of the variance within the in situ data can be interpreted by the derived equation $\left(\mathrm{R}^{2}=0.69, \mathrm{p}=0.00, \mathrm{~N}=264\right)$ and the RMSE of Chl-a estimates is $0.24 \mathrm{mg} . \mathrm{m}^{-3}$ that is equivalent to a MAPE of $16.5 \%$. The validation demonstrates the accuracy of the SPP algorithm in estimating Chl-a concentrations for phytoplankton assemblages. 


\section{Results}

\subsection{Assessment of satellite chlorophyll products}

The previous section showed the result of the algorithm calibration and validation. It is necessary to evaluate the accuracy of the SPP Chl-a retrievals in the comparison with the standard Chl-a products generated for the Baltic Sea. Therefore, the satellite Chl-a obtained from the MERIS Algal-2, MERIS C2R processor and MODIS OC4 algorithm together with the SPP Chl-a estimates are compared against in situ observations. To avoid dependence on the calibration dataset, only the validation datasets are used. The dataset is comprised of the concurrent measurements taken from two Baltic regions: the Baltic Proper and the Gulf of Bothnia.

To better demonstrate the performance of each algorithm, the match-up dataset is separated into two subsets based on the region where it was taken. The first dataset contains the data collected in the Gulf of Bothnia, which is known to have higher CDOM concentrations (Kowalczuk et al., 2005, 2006), the second dataset was collected from the Baltic Proper. The comparison results are presented in Figure 4
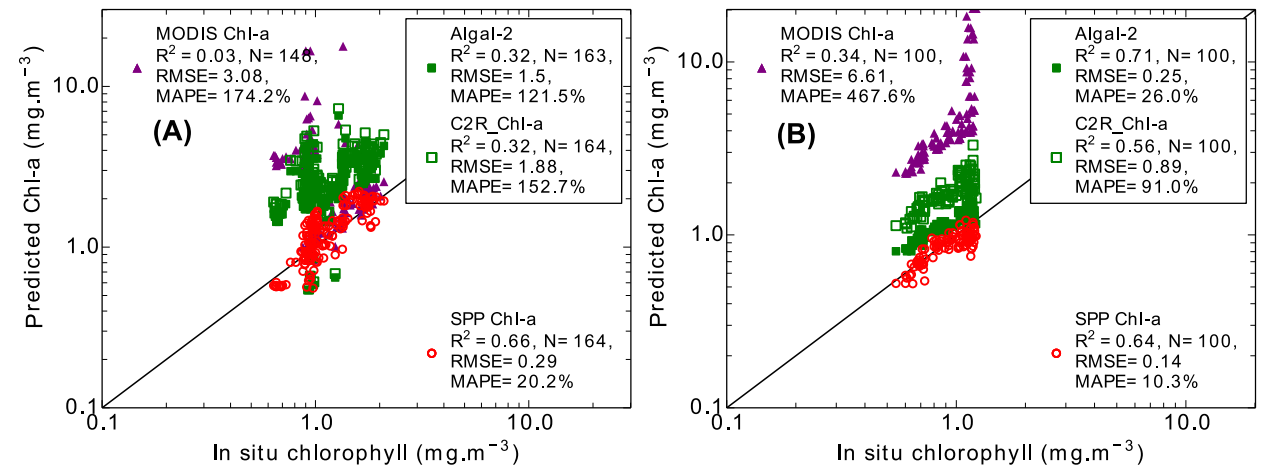

Figure 4: The comparison of the MERIS Algal-2, MERIS C2R, MODIS OC4 and SPP Chl-a estimates derived from the Baltic Sea. Panels A shows the results using the data collected from the Bothnian Sea, and Panel B present the results for the Baltic Proper. 
It can be seen from Panel A Figure 4 that MODIS OC4 Chl-a concentrations show no correlation with the near-concurrent in situ observations in the CDOM dominated Gulf of Bothnia, and have the highest error $\left(\mathrm{R}^{2}=0.03\right.$, $\mathrm{N}=148, \mathrm{RMSE}=3.08 \mathrm{mg} \mathrm{m}^{-3}, \mathrm{MAPE}=174.2 \%$ ). The MERIS Algal-2 and the Case II regional chlorophylls show a similar performance, both have $\mathrm{R}^{2}$ values of 0.32 . However, the error in the $\mathrm{C} 2 \mathrm{R}$ Chl-a retrievals is higher $(\mathrm{RMSE}=1.88$, MAPE $=152.7 \%$ ) than that of Algal-2, which has an RMSE and MAPE of 1.5 and $121.5 \%$, respectively. An improved Chl-a estimation is made by the SPP algorithm. It has a $\mathrm{R}^{2}$ value of $0.66(\mathrm{~N}=164)$, and the error in the Chl-a estimation is the lowest $(\mathrm{RMSE}=0.29, \mathrm{MAPE}=20.2 \%)$. Note that the difference in sample numbers is due to the exclusion of invalid Chl-a estimates from the MODIS OC4 and MERIS Algal-2 products.

In Panel B Figure 4, the three Chl-a retrievals show good agreement with the in situ observations, except the MODIS OC4 that has a $\mathrm{R}^{2}$ value of 0.34 $(\mathrm{N}=100)$ with a RMSE of $6.61 \mathrm{mg} \mathrm{m}^{-3}$ and a MAPE of more than $400 \%$. As for the MERIS Chl-a estimates, both of the Algal-2 $\left(\mathrm{R}^{2}=0.71, \mathrm{~N}=100\right)$ and $\mathrm{C} 2 \mathrm{R}$ algorithm $\left(\mathrm{R}^{2}=0.56, \mathrm{~N}=100\right)$ have good correlations with the in situ measurements, especially Algal-2 that has a RMSE of $0.25 \mathrm{mg} \mathrm{m}^{-3}$ that is equivalent to a MAPE of $26 \%$. In this case, the $\mathrm{R}^{2}$ and RMSE of the SPP Chl-a retrievals are 0.64 and $0.14 \mathrm{mg} \mathrm{m}^{-3}$, which is equal to a MAPE of $10.3 \%$. Table 2 presents the statistical comparison between the three Chl-a retrievals predicted for the Bothnian Sea and Baltic Proper.

\subsection{CyanoBloom_flag testing}

In order to demonstrate the performance of the flagging method for detecting the spatial distributions of surface blooms and scums, a cloud free MERIS image collected on 3rd August 2011 was used to produce the corresponding CyanoBloom_flag image. Ideally, the extent of surface blooms and scums should 
Table 2: Statistical comparison between different Chl-a products generated for the Bothnian Sea and Baltic Proper.

\begin{tabular}{cccccc}
\hline Region & Product Name & RMSE $\left(\mathbf{m g} \cdot \mathbf{m}^{-3}\right)$ & MAPE $(\%)$ & $\mathbf{R}^{2}$ & $\mathbf{~ N}$ \\
\hline Bothnian Sea & MODIS OC4 & 3.08 & 174.2 & 0.03 & 148 \\
Bothnian Sea & MERIS Algal-2 & 1.5 & 121.5 & 0.32 & 163 \\
Bothnian Sea & MERIS C2R & 1.88 & 152.7 & 0.32 & 164 \\
Bothnian Sea & SPP Chl-a & 0.29 & 20.2 & 0.66 & 164 \\
\hline Baltic Proper & MODIS OC4 & 6.61 & 467.6 & 0.34 & 100 \\
Baltic Proper & MERIS Algal-2 & 0.25 & 26 & 0.71 & 100 \\
Baltic Proper & MERIS C2R & 0.89 & 91 & 0.56 & 100 \\
Baltic Proper & SPP Chl-a & 0.14 & 10.3 & 0.64 & 100 \\
\hline
\end{tabular}

be validated using concurrent in situ data. Unfortunately, this is not practical in the Baltic Sea as field survey platforms such as research vessels can significantly disturb natural distributions of surface blooms and/or scums, resulting in bloom and scum samples being uncollectable, hence the false representation of the sampled areas (Kutser, 2009). Due to this difficulty, the MERIS Full Resolution (FR) image (spatial resolution of $300 \times 300 \mathrm{~m}$ ) is used to create a TC composite for the visual validation.

It can be seen from Panel A Figure 5 that dense surface blooms appeared in the north-west part of the Baltic Proper and extended into the Gulf of Finland. The visual examination for the reflectance spectra of these waters showed that they are characterised by distinct reflectance troughs at $681 \mathrm{~nm}$, with a reflectance peak either at $709 \mathrm{~nm}$ or $754 \mathrm{~nm}$; whereas for the rest water, they either possess the $681 \mathrm{~nm}$ reflectance peaks or have relative constant reflectance shapes in the red and NIR regions.

Furthermore, the bright-green pixels of the bloom waters presented in Panel A have the higher reflectance magnitudes at $754 \mathrm{~nm}$ than that at $709 \mathrm{~nm}$, and the surrounding green pixels have clearly discernible $709 \mathrm{~nm}$ reflectance peaks, 

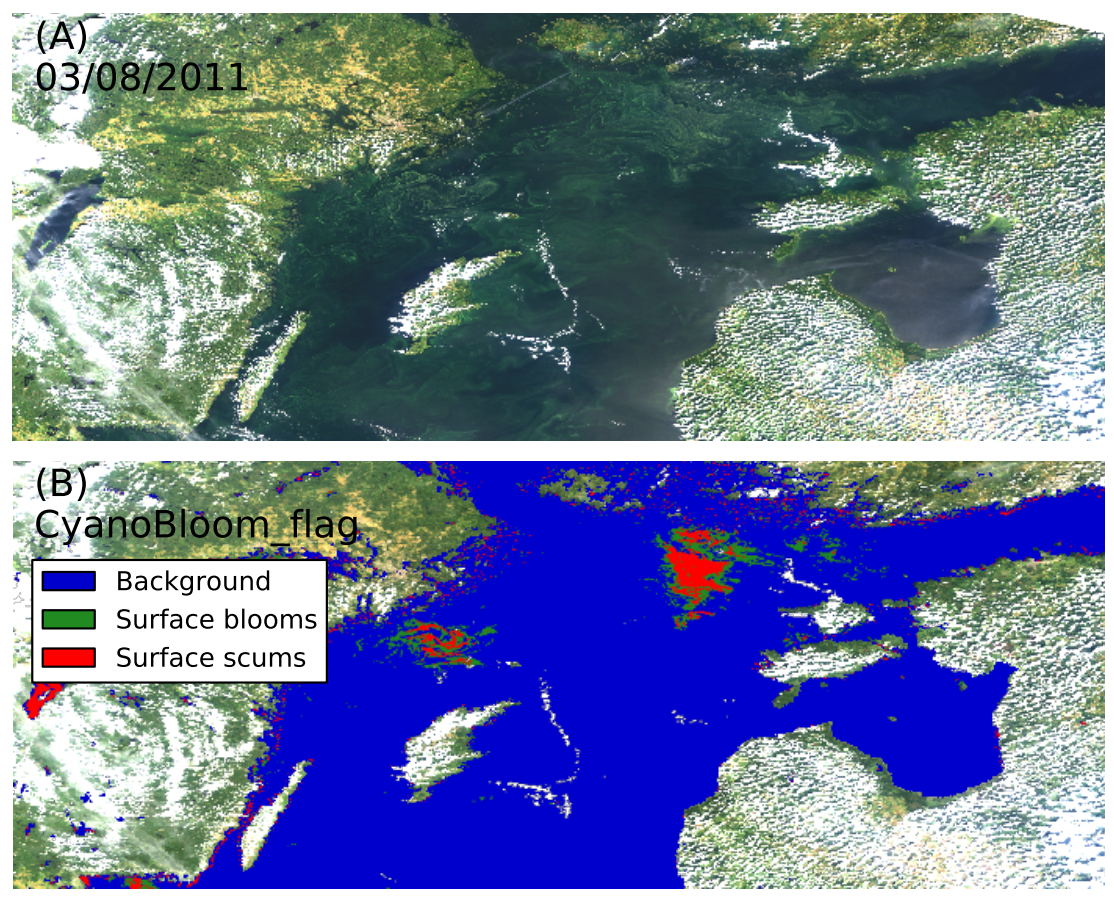

Figure 5: The performance of the CyanoBloom_flag in mapping surface blooms and scums in the Baltic Sea. Panel A shows a MERIS full resolution TC composite derived from MERIS bands 7 (red), 5 (green) and 2 (blue). Panel B presents the corresponding CyanoBloom_flag image, where the background water, surface bloom and scum pixels are shown in blue, green and red respectively.

with reduced $754 \mathrm{~nm}$ reflectance magnitudes. As for the bright-green pixels, they are all identified as surface scums, shown in red in Panel B; as for the green pixels, they are identified as surface blooms, presented in green colour in Panel B. Interestingly, most of the identified bloom and scum pixels also have the $665 \mathrm{~nm}$ reflectance peaks, which is thought to the sun-induced PC fluorescence (Kutser et al., 2006; Qi et al., 2014). Note that the identified scum pixels aligned with the shoreline are the actual coastlines according to the L1B coastline flag identification. Thus, these pixels should be neglected. 


\subsection{SPP variables from low-to-medium phytoplankton biomass waters}

To demonstrate the algorithm's performance in retrieving Chl-a concentrations from low-to-medium phytoplankton biomass waters, an alternative baseline subtraction approach termed MPH (Matthews et al., 2012) is selected for the comparison. The in situ dataset collected on 8th July 2010 spanning a Chl-a range from 0.5 to $1.5 \mathrm{mg} \mathrm{m}^{-3}$ was used to represent the case of low-to-medium biomass waters. As the MPH algorithm was not parameterised for the Baltic Sea, the original variables derived from the two approaches are used to compare against the in situ measurements. As can be seen from Figure 6, the correlation between the MPH variables and in situ Chl-a is negligibly small $\left(\mathrm{R}^{2}=0.0\right.$, $\mathrm{N}=114$ ); whereas for the SPP variables, $72 \%$ of the variance of the in situ data is interpreted $\left(\mathrm{R}^{2}=0.72, \mathrm{~N}=114\right)$. Despite that there is no overall correlation between the MPH variables and in situ data, the derived variables are covariant with in situ Chl-a when the concentration is below $0.7 \mathrm{mg} \mathrm{m}^{-3}$. This is because that the chlorophyll fluorescence band is the only channel that produces an observable peak, and the other bands have negative reflectance line heights. This means that the two algorithms essentially calculate the same reflectance line height at $681 \mathrm{~nm}$. When Chl-a concentration becoming higher than $0.7 \mathrm{mg}$ $\mathrm{m}^{-3}$ and the $709 \mathrm{~nm}$ backscattering overcomes water absorption, two positive reflectance line heights are measurable in MERIS bands 8 (681 nm) and 9 (709 $\mathrm{nm})$, see Panel B Figure 2 for example.

\subsection{SPP Chl-a retrievals from cyanobacteria dominant waters}

Due to the limited range of in situ Chl-a data used for the algorithm calibration and validation, it is also necessary to assess the algorithm's accuracy in retrieving Chl-a from high biomass phytoplankton assemblages such as surface blooms and scums. Therefore, the MERIS image acquired on 20th July 2010 that includes surface blooms and scums (according to the identification of the 


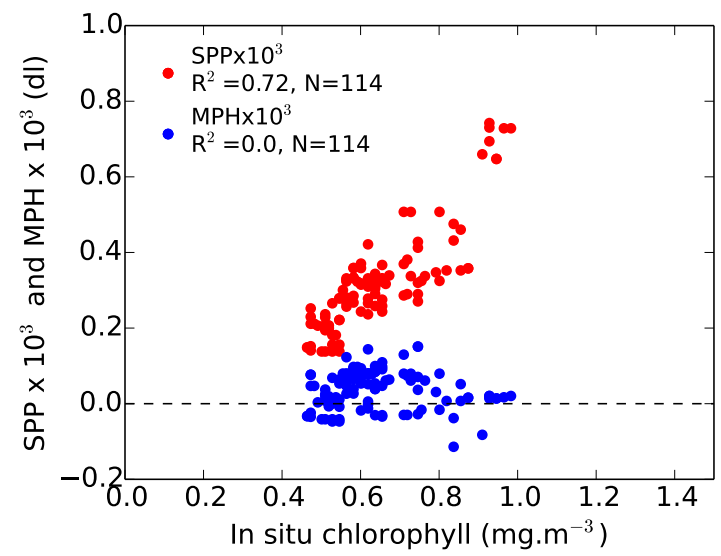

Figure 6: Comparison between the SPP and the MPH with the in situ Chl-a collected on 8th July 2010. The horizontal dashed line on the figure shows $\mathrm{Y}=0$.

CyanoBloom_flag) is selected to extract SPP Chl-a retrievals from an artificial defined ship transect. The artificially defined transect crosses surface bloom and scums in the south Baltic Proper, see Panel A Figure 7, where the SPP Chl-a estimates span a range of $\sim 1$ to $50 \mathrm{mg} \mathrm{m}^{-3}$. In the assessment, the operational MERIS-based NIR/red ratio algorithm, also known as the advanced two-band MERIS NIR-red algorithm (Moses et al., 2012), is used to produce the corresponding Chl-a estimates along the ship transect. This algorithm was chosen for the comparison as it has been parameterised for highly productive waters, with the ability to retrieve Chl-a concentrations up to $110 \mathrm{mg} \mathrm{m}^{-3}$. As MERIS L2 reflectance data are generally invalid for the Baltic Sea and the two-band NIR-red algorithm needs $\mathrm{R}_{r s}$ as the input parameter, therefore, the simple atmospheric normalisation procedure of subtracting BRR14 from BRR7 and BRR9 is used to roughly obtain $R_{r s}(665)$ and $R_{r s}(709)$. Note that this procedure also produces a number of invalid reflectance values that are excluded from the analysis.

It can be seen from Panel B Figure 7 that the Chl-a retrievals from the two algorithms are highly covariant $\left(\mathrm{R}^{2}=0.5, \mathrm{~N}=173\right)$ and within the Chl-a range 

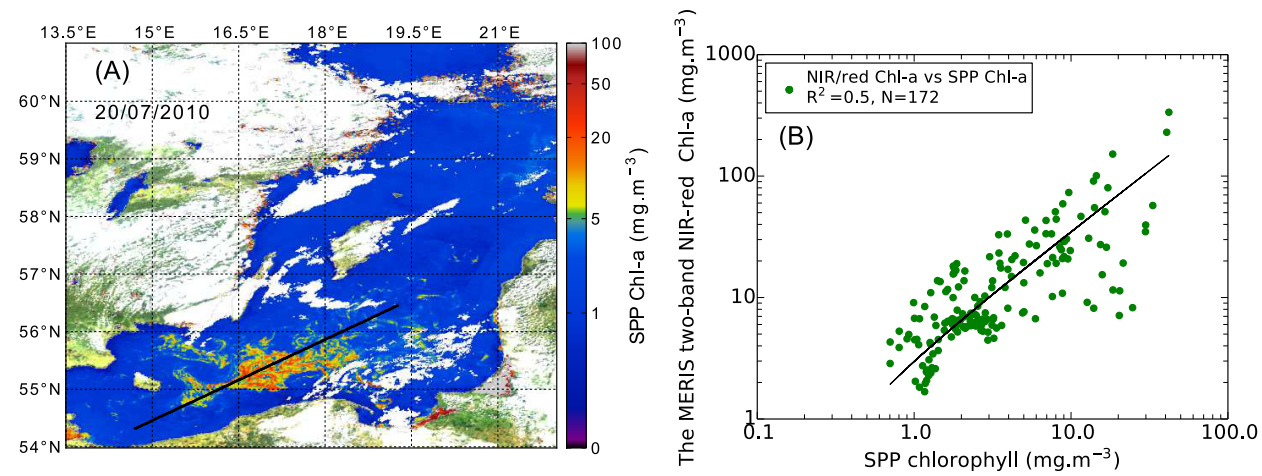

Figure 7: MERIS SPP Chl-a image acquired on 20th July 2010 (Panel A) and the comparison result between SPP and the two-band NIR/ratio algorithm. The overlaid blackline on Panel A defines the artificial ship transect.

from approx. 1 to $60 \mathrm{mg} \mathrm{m}^{-3}$. However, the two-band NIR-red algorithm has consistently higher Chl-a estimates than the SPP algorithm, and the maximum bias factor between the two algorithms is around 10-fold. This is probably due to the poor atmospheric correction applied. Also, the coefficients of the advanced two-band MERIS NIR-red algorithm tuned for turbid productive waters may not be suitable for the Baltic Sea. Indeed, a number of studies have shown that the specific absorption coefficient of phytoplankton varies significantly with the composition of phytoplankton assemblages as well as the trophic status of water bodies (Bricaud et al., 1995, 2004). Such variation in the phytoplankton specific absorption coefficient directly affects the algorithm coefficient tuning for specific regions, hence resulting in the bias in Chl-a estimates. However, being an operational algorithm, the advanced two-band MERIS NIR-red algorithm is potentially useful for providing Chl-a estimates for turbid regions within the Baltic Sea, such as coastal lagoons where concentrations of suspended particles are known to be high. These preliminary results suggest that the SPP algorithm may still have the ability to provide Chl-a estimates for cyanobacteria dominant waters with the upper detection limit of $50 \mathrm{mg} \mathrm{m}^{-3}$, but in situ datasets with wider Chl-a ranges are needed for the conclusion. 


\subsection{Application examples in the study site}

It has been reported that dense surface blooms reached an unprecedented extent in the central Baltic Sea during the summer of 2005 (Kahru et al., 2007). The field campaign undertaken by SYKE reported that toxic Nodularia spumigena blooms were observed in the central Bothnian Sea in late July of the same year. Although dense cyanobacterial blooms are known to occur less frequently in the Gulf of Bothnia, compared with the central region, it is still necessary to test the algorithm's performance for this region. Therefore, a series of MERIS images taken from the Baltic Proper and Gulf of Bothnia in July 2005 were acquired. As shown in the first four panels in Figure 8, dense surface blooms are observed in the central Baltic Sea, with the estimated Chl-a values being above $\sim 50 \mathrm{mg} \mathrm{m}^{-3}$. The retrieved bloom distribution shows good agreements with the TC composites, although a large proportion of MERIS imagery was contaminated by sun glint.

The final case is made for Nodularia spumigena blooms in the Gulf of Bothnia on 30th and 31st July 2005 (see Panels E and F). SPP Chl-a estimates correctly identified the less intense blooms in the central Bothnian Sea, which has been confirmed by in situ observations ${ }^{1}$. However, the Chl-a estimates from MERIS Algal-2 products (see Panels G and H) show inconsistent surface bloom distributions, having completely different bloom patterns to that shown in the corresponding TC composites and SPP Chl-a images.

\footnotetext{
${ }^{1}$ See the report of field campaign http://www.itameriportaali.fi/en/ajankohtaista/ uutisia_muualta/2005/en_GB/843/
} 

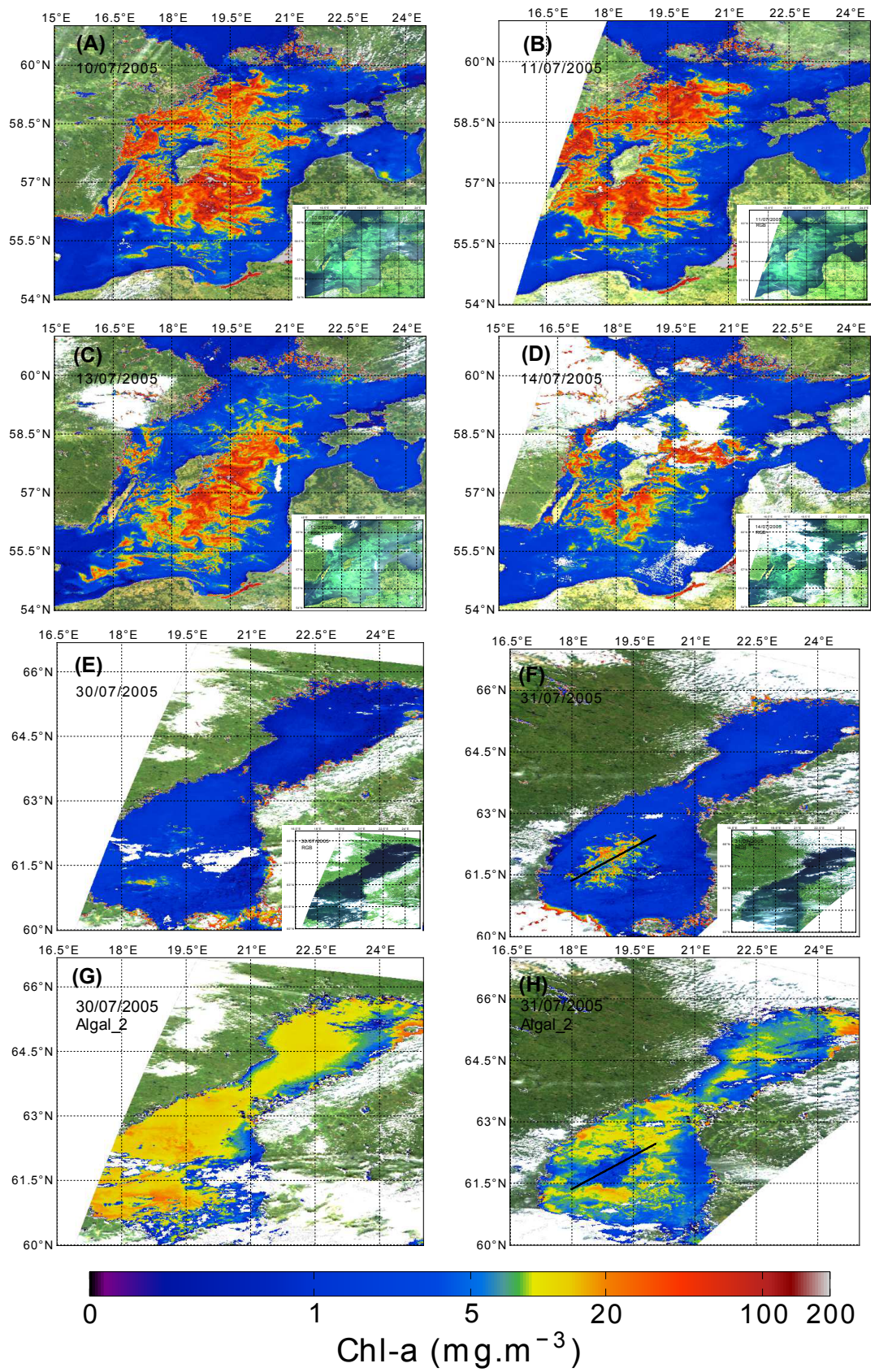

Figure 8: Application of the SPP algorithm to the Baltic Sea in determining phytoplankton abudances under various atmospheric conditions. The inset image on each panel shows the corresponding TC composite derived from MERIS bands 7 (red), 5 (green), 2 (blue). Panels A-D show the examples in the central Baltic Sea. Panels E and F represent examples from the Gulf of Bothnia. Panels $\mathrm{G}$ and $\mathrm{H}$ show Chl-a retrievals from the MERIS Algal-2 algorithm. The overlaid lines on panels $\mathrm{F}$ and $\mathrm{H}$ are the artificial transects showing inconsistent bloom distributions. 


\section{Discussion}

\subsection{Reliability of satallite chlorophyll products}

\subsubsection{MODIS blue-green band ratio algorithm}

Results from the comparison of satellite Chl-a with in situ observations (Figure 4) showed that the operational MODIS OC4 algorithm had very poor performance in retrieving Chl-a concentrations, suggesting the MODIS Chl-a product is not directly usable in the Baltic Sea.

The MODIS OC4 algorithm (OReilly et al., 2000), developed on the basis of the absorption and backscattering features in the blue and green regions, was originally designed for assessing Chl-a in open oceans where phytoplankton is optically dominant. The reason to include the MODIS OC4 chlorophyll product in the inter-comparison was to test the degree to which the known issues of CDOM affect the performance of a standard algorithm designed for open oceans. Indeed, in the central Baltic Sea where the terrestrial inputs are less dramatic compared with the coastal gulfs, the MODIS OC4 Chl-a had good covariance with in situ observations, having the overestimation up to 20 -fold. This result implies that the blue-green band ratio type approach is potentially applicable to the open region of the Baltic Sea in the conditions that the water is relatively clear with no surface blooms occuring and the coefficients are localised.

However, the covariance disappeared when the algorithm was applied to the Gulf of Bothnia where yellow substances are known to be high. The absorption spectra of yellow substances (or CDOM) is characterised by an exponential shape decreasing from the blue $(\sim 400 \mathrm{~nm})$ to NIR region. In the spectral region between 440 and $600 \mathrm{~nm}$, phytoplankton indicated by Chl-a also possesses a qausi exponential decreasing trend in the absorption coefficient that is similar to CDOM. In optically CDOM dominant waters, increasing concentrations in either CDOM or Chl-a would lead to the blue-green reflectance peak to shift 
from the blue region towards the green region. The MODIS OC4 algorithm, using the ratio of the maximum reflectance measured at wavelengths of 443 , 490 and $510 \mathrm{~nm}$ to the reflectance measured at $555 \mathrm{~nm}$, is not able to separate water-leaving signals resulted from Chl-a and CDOM, as no inversion model is available. Thus, a general outcome of the application of the blue-green band ratio algorithm to CDOM dominant waters would result in overestimated Chl-a concentrations.

\subsubsection{MERIS chlorophyll products}

The operational scheme applied by the MERIS sensor for producing the Algal-2 and C2R products was developed on the basis of a Neural Network (NN) approach (Doerffer \& Schiller, 2007). The algorithm derives inherent optical properties (IOPs) from a trained NN for three optically active water constituents, including absorption coefficients of phytoplankton pigments, yellow substance and bleached particulate matter. All these IOPs are defined at the wavelength of $442 \mathrm{~nm}$ for MERIS band 2, and subsequent satellite products such as water constituent concentrations are derived from several pre-defined empirical relationships with the IOPs.

As shown in Figure 4, Chl-a concentrations derived from the Algal-2 and $\mathrm{C} 2 \mathrm{R}$ products were well correlated with in situ data, especially the estimation made in the Baltic Proper, see Panel B Figure 4. Whereas for the north Baltic basin: the Gulf of Bothnia, Chl-a from the two products generally had higher Chl-a estimates than the near concurrent in situ observations, see Panel A Figure 4. This is probably because bio-optical properties of the Gulf of Bothnia are out of the scope of the training sets, resulting in inappropriate IOPs being applied to estimate Chl-a. As stated by (Doerffer \& Schiller, 2007), the training sets applied to the NN training were primarily collected from the North Sea and some other European waters, and only a few of the sets were collected from the 
south Baltic Sea.

Another factor that can cause the overestimation of the two chlorophyll products in the comparison may result from the in situ data collected at a depth of 3 m. However, Alikas et al. (2015) and Alikas \& Kratzer (2017) demonstrated that monthly means of the first optical depth of the north-west Baltic region and Bothnian Sea (i.e. the region where the in situ data were obtained) are generally deeper than $3 \mathrm{~m}$ except the month July. Therefore, the discrepancy between the datasets is unlikely to be the key factor resutling in the overestimation, if the water samples were collected from the well mixed water column with no surface blooms occuring during sampling days in July. It is worth noting that the comparison results shown in Figure 4 were based on the data collected in June and August.

In addition to the effect of training sets, insufficient atmospheric correction and the occurrence of algal blooms can also cause bias and exceptions in Chl-a in the Algal-2 products. Indeed, in late July 2005 when surface blooms and cloudy atmosphere occurred in the Gulf of Bothnia, the chlorophyll map of the Algal-2 product falsely represented the spatial distributions of bloom areas (Panel G and $\mathrm{H}$ in Figure 8) and Chl-a estimated along the artificially defined ship track was inversely correlated with the SPP Chl-a. Therefore, caution needs to be applied to MERIS Algal-2 product when using it to study phytoplankton abundances in the Gulf of Bothnia.

\subsection{Phytoplankton abundance from ocean colour indices}

Being an empirical TOA type method, various baseline subtraction algorithms have been developed for estimating Chl-a concentrations in optically complex inland and coastal waters. These algorithms usually take advantage of Chl-a related spectral features observed in the red and NIR regions to establish empirical relationships between the measured reflectance peak height 
and Chl-a concentrations. Despite the fact that these algorithms avoids the need for fully atmospheric corrected spectral data and can be simply applied to various waters, the limitation is evident when using it to study phytoplankton dynamics on the basis of the single reflectance peak height measured. This is because the shift of distinct reflectance peak from the red to NIR region when phytoplankton biomass becomes abundant, shown in Figure 2. To overcome the weakness of single-band based subtraction algorithms, the recently developed MPH approach considers multi-spectral signals observed in red and NIR regions and utilises the maximum reflectance peak height to determine Chl-a concentrations. The approach works very well in eutrophic and/or hypertrophic waters. However, in low-medium biomass waters where the maximum reflectance peak located in the SICF band, phytoplankton abundances may not be accurately retrievable due to the weak signal observed, see Figure 6.

Instead of measuring a single red and NIR reflectance peak height, the currently proposed SPP algorithm takes advantage of the sum of all the positive signal line heights for estimating phytoplankton abundance. The comparison results demonstrated that the SPP approach performed better over the standard satellite chlorophyll products (Figure 4) and sensitive to phytoplankton abundance changes in low-medium biomass waters in the Baltic Sea, see Figure 6, suggesting that the algorithm is potentially suitable for studying phytoplankton bloom initiation.

As for the case where surface cyanobacterial blooms and/or scums formed, the currently proposed SPP approach may not able to provide accurate Chl-a estimates. This is not only due to the limited in situ data available for the algorithm calibration and validation, but also the challenge to collect and extract chlorophyll pigments from cyanobacteria dominant phytoplankton assembages (Kutser, 2009; Simis et al., 2007). Therefore, an alternative method of 
CyanoBloom_flag is proposed for qualitatively detecting spatial distributions of surface blooms and/or scums based on the appearance of the reflectance trough in SICF band. Such a spectral shape of the SICF trough is considered as the result of cyanobacterial bloom occurring (Wynne et al., 2008). The negative spectral feature has been used to determine bloom intensities in inland lakes (Wynne et al., 2010; Stumpf et al., 2012).

Considering the observed reflectance from surface scums resembles land vegetation spectral shapes, and the water-leaving signal from surface blooms is negligibly small beyond the wavelength of $750 \mathrm{~nm}$, thus, the two types of blooms can be roughly differentiate from one of the other. As can be seen from Figure 5 that the detected surface scums are usually surrounded by surface blooms, which is coherent with the natural situation that surface scums and/or floating algae are the extreme case of surface blooms

Compared with MERIS, the recently launched OLCI is optimised for better ocean colour measurements over optically complex inland and coastal waters. The SPP algorithm should be directly transferable to OLCI imagery, and the new band configured at $674 \mathrm{~nm}$ for the improved SICF measurement shall provide an insight into TOA type algorithm development.

\subsubsection{Impacts of the physiological state and environmental factors on SICF}

As a byproduct of photosynthesis, SICF produced by phytoplankton has long been used for estimating primary production and Chl-a concentrations (Neville \& Gower, 1977; Booth, 1989; Falkowski \& Kolber, 1995; Chamberlin et al., 1990; Chamberlin \& Marra, 1992; Kiefer \& Reynolds, 1992; Letelier \& Abbott, 1996). For instance, it is known that the rate of photosynthesis varies with the rate of natural fluorescence, and the fluorescence quantum yield efficiency is inversely correlated with photosynthetic quantum efficiency. However, the prediction of the photosynthetic quantum efficiency is not a trivial task. Geo- 
physical processes (such as the availability of nutrients) and diurnal variations in the fluorescence quantum yield make the application of natural fluorescence to primary production estimation less effective in global waters (Stegmann et al., 1992; Falkowski \& Kolber, 1995).

In addition, it has also been suggested that the natural fluorescence may not be useful for the detection of spatial and temporal variations in phytoplankton abundances, even in oligotrophic marine environments. In particular, the rate of Chl-a fluorescence is dependent on two factors: the light flux absorbed by the photosystem (primarily by PS II) and the fluorescence quantum yield (the fraction of photons fluoresced by Chl-a to photons absorbed by all pigments). Under light saturated conditions, the absorbed light flux is assumed to be constant, thus, the fluorescence signal per unit Chl-a is proportional to the fluorescence quantum yield ${ }^{2}$. From a satellite remote sensing perspective, Chl-a concentrations derived from the natural fluorescence or the FLH algorithm are under an assumption that the fluorescence quantum yield is constant, in other words, the ratio of fluorescence to Chl-a is assumed to be invariant. In most cases, however, fluorescence quantum yield is highly variable. For instance, Borstad et al. (1985); Babin et al. (1996) have stated that changes in phytoplankton species composition, nutrient concentrations and the availability of ambient light can cause significant variations to the fluorescence quantum yield. In addition, the physiological state of phytoplankton assemblages is another source causing the variability to the fluorescence quantum yield (Suggett et al., 2009).

Clearly, the variability in fluorescence quantum yield related to phytoplankton physiology and environmental conditions results in difficulties in the interpretation of the observed fluorescence signal, and introduces complications in using natural fluorescence for retrieving Chl-a. However, a recent study (Giler-

${ }^{2}$ SICF per Chl-a concentration=const. $\times$ fluorescence quantum yield 
son et al., 2007) of the HYDROLIGHT simulation has shown that the variability of the fluorescence quantum yield is relatively stable in coastal waters, having a value of around 0.01 . The study also indicates that the variation in fluorescence quantum yield is less significant to cause changes to the natural fluorescence compared to the signal attenuation in the water column. Although McKee et al. (2007) has suggested that increased concentrations of yellow substances and non-algal particles can cause the natural fluorescence per Chl-a to decrease by more than $50 \%$, their study shows that the FLH is less prone to variations in CDOM concentrations. These results imply that the assumption of the constant ratio of fluorescence to Chl-a is applicable to the retrieval of Chl-a concentrations. The results from the algorithm calibration and validation indicate that using peak height of fluorescence provides good Chl-a estimates in the Baltic Sea, given that in situ datasets were collected from different regions.

\subsubsection{Impact of suspended particles on the $709 \mathrm{~nm}$ signal in the Chl-a retrievals}

In the Baltic Sea, riverine inflow from the southern catchment areas persistently brings in inorganic materials and detrital particles to the coastal and shallow zones and causes re-suspension of bottom sediments in the water column. Such substantial amounts of suspended particles, resulting in the increase of water turbidity, could give rise to inaccurate SPP Chl-a estimates.

As shown in Figure 8, the two lagoons located in the southeast of the Baltic Sea had consistently high SPP Chl-a concentrations during summer. Therefore, Chl-a concentrations derived in these turbid productive waters may not be accurate, because of the interference of suspended materials to the observed signal. It is acknowledged that suspended matter is related to the primary production, sediment transport and water clarity, and can be used as an indicator of water quality (Dekker et al., 2002). However, using the empirical baseline subtraction approach such as the SPP and MCI algorithm for deriving Chl-a concentrations 
from turbid waters may have issues, due to the difficulty in using the current satellite data to separate the signals of phytoplankton and suspended matter. In suspended particle dominant waters, the reflectance spectra are characterised by a distinct peak observable at 700 nm (Doxaran et al., 2003; Härmä et al., 2001), resembling the backscattering from phytoplankton. The similarity in the spectral shapes can cause significant ambiguity between Chl-a and suspended particle retrievals, as the baseline subtraction algorithm is not able to distinguish one from the other, and miscounts the peak height as phytoplankton.

Not only causing ambiguity to Chl-a retrievals, strong backscattering from suspended matter also make atmospheric correction over Case II waters challenging. The direct application of an atmospheric correction scheme designed for open oceans to turbid coastal and inland waters would not yield accurate reflectance data. Furthermore, the geographical nature of turbid coastal zones and inland waters (the high contrast between land and water scenes) also complicates atmospheric correction procedures. However, the high spectral resolution and the additional NIR and SWIR bands available on new satellite sensors can provide an insight into improving Chl-a estimation and atmospheric correction in turbid productive waters.

\section{Conclusion}

In conclusion, a new method termed Summed Positive Peaks is proposed to retrieve Chl-a concentrations for determining phytoplankton abundances in an optically complex coastal water, the Baltic Sea. The results demonstrate that the red and NIR spectral features such as SICF and $709 \mathrm{~nm}$ backscattering can provide reasonable Chl-a estimates for phytoplankton abundance assessments using a baseline subtraction approach. The calculation of the SPP variables based upon the TOA type approach is an effective means to normalise 
atmospheric effects under the assumption that atmospheric aerosol effects are relatively constant at the red and NIR wavelengths used. Thus, the Rayleigh corrected TOA dataset is efficient for the phytoplankton abundance estimation, and it can be employed as an alternative dataset that avoids complicated and error-prone atmospheric aerosol corrections for phytoplankton-oriented water quality monitoring programmes in Baltic regions.

Additionally, the red and NIR spectral reflectance features observed by MERIS during the period studied enabled Chl-a concentrations to be estimated for eukaryote dominated, cyanobacteria dominated and mixed eukaryote and cyanobacteria waters. This is achieved through the calculation of the reflectance magnitude differences over the predefined baseline, and the summation of the positive line heights. Based on the sign of the calculated SCIF line height, and the reflectance difference between MERIS bands 9 and 10, the CyanoBloom_flag is proposed to deal with intensive surface blooms and scums and/or floating algae. The results from the algorithm calibration and validation, with the near-coincident in situ observations, suggest that the algorithms Chl-a retrieval range is from 0.5 to $4 \mathrm{mg} \mathrm{m}^{-3}$ with an RMSE of $0.24 \mathrm{mg} \mathrm{m}^{-3}$. Due to limited in situ measurements being available, the advanced two-band MERIS NIR-red approach is further used to confirm that the practical Chl-a retrieval limit of the SPP algorithm is up to $50 \mathrm{mg} \mathrm{m}^{-3}$. As for the extreme case, the proposed CyanoBloom flag provides the spatial distribution of surface blooms, and discriminates bloom and scum waters from the background. The comparison with standard satellite chlorophyll products and MPH approach reveals the algorithms robustness and sensitivity to phytoplankton abundance changes in low-to-medium biomass waters. These results indicate that the SPP approach is potentially suitable for detecting the initiation of phytoplankton blooms. Furthermore, the Baltic Sea examples demonstrate the algorithms performance in 
estimating phytoplankton abundances under various atmospheric conditions in different time periods. Therefore, it is proposed that this approach is also potentially suited for phytoplankton related real-time water quality monitoring.

Overall, the SPP approach is demonstrated as a novel empirical algorithm for determining phytoplankton abundance in an optically complex coastal water, the Baltic Sea. This is one of a few studies showing the significant correlation between the empirical derived Chl-a concentration and the TOA variable determined through the red and NIR signals from MERIS observations. The advantages of this TOA type approach are not only evident in processing time, but it also avoids the errors potentially introduced during atmospheric correction procedures. The findings from this research have significant implications for the study of long-term phytoplankton bloom dynamics in the Baltic water based on historical MERIS observations and for the development of phytoplankton oriented near-realtime water quality monitoring programmes and warning systems using the Copernicus Sentinel-3 OLCI.

\section{Acknowledgements}

The authors would like to express their gratitude to Plymouth Marine Laboratory; Dr. Giorgio Dall'Olmo for his invaluable advice on this study and Steve Groom for his kind support. The authors also would like to thank the ship captain and crew for assisting in situ measurements, Dr. Susanne Kratzer (Stockholm University) for helpful advice on acquiring the in situ data, and four anonymous reviewers for their constructive comments towards improving this work. The satellite imagery is provided by the European Space Agency and the NASA Goddard Space Flight Centre, and this work was partly supported by the UCL MAPS Dean's fund. 
Abeliovich, A. t., \& Shilo, M. (1972). Photooxidative death in blue-green algae. Journal of bacteriology, 111, 682-689.

Al-Naimi, N., Raitsos, D., Ben-Hamadou, R., \& Soliman, Y. (2017). Evaluation of Satellite Retrievals of Chlorophyll-a in the Arabian Gulf. Remote Sensing, 9,301 .

Alikas, K., Kangro, K., \& Reinart, A. (2010). Detecting cyanobacterial blooms in large North European lakes using the Maximum Chlorophyll Index. Oceanologia, 52, 237-257.

Alikas, K., \& Kratzer, S. (2017). Improved retrieval of Secchi depth for opticallycomplex waters using remote sensing data. Ecological Indicators, 77, 218-227.

Alikas, K., Kratzer, S., Reinart, A., Kauer, T., \& Paavel, B. (2015). Robust remote sensing algorithms to derive the diffuse attenuation coefficient for lakes and coastal waters. Limnology And Oceanography-Methods, 13, 402-415.

Arvola, L. (1981). Spectrophotometric determination of chlorophyll a and phaeopigments in ethanol extraction. Ann. Bot. Fennici, 18, 221-227.

Babin, M., Morel, A., \& Gentili, B. (1996). Remote sensing of sea surface Suninduced chlorophyll fluorescence: Consequences of natural variations in the optical characteristics of phytoplankton and the quantum yield of chlorophyll a fluorescence. International Journal Of Remote Sensing, 17, 2417-2448.

Bailey, S. W., \& Werdell, P. J. (2006). A multi-sensor approach for the onorbit validation of ocean color satellite data products. Remote Sensing of Environment, 102, 12-23.

Binding, C. E., Greenberg, T. A., Jerome, J. H., Bukata, R. P., \& Letourneau, G. (2011). An assessment of MERIS algal products during an intense bloom in Lake of the Woods. Journal Of Plankton Research, . 
Booth, C. (1989). Natural fluorescence of chlorophyll \&i: Relationship to photosynthesis and chlorophyll concentration in the western south pacific gyre. Limnol. Oceanogr, 34, 868-881.

Borstad, G. A., Edel, H., Gower, J. F., \& Hollinger, A. (1985). Analysis of test and flight data from the Fluorescence Line Imager volume 83. Can. Spec. Publ. Fish. Aquat. Sc.

Brewin, R. J., Raitsos, D. E., Pradhan, Y., \& Hoteit, I. (2013). Comparison of chlorophyll in the red sea derived from modis-aqua and $i_{i}$ in vivoi $/ i_{i}$ fluorescence. Remote Sensing of Environment, 136, 218-224.

Bricaud, A., Babin, M., Morel, A., \& Claustre, H. (1995). Variability in the chlorophyll-specific absorption coefficients of natural phytoplankton: Analysis and parameterization. Journal of Geophysical Research, 100, 13321-13332.

Bricaud, A., Claustre, H., Ras, J., \& Oubelkheir, K. (2004). Natural variability of phytoplanktonic absorption in oceanic waters: Influence of the size structure of algal populations. Journal of Geophysical Research: Oceans (19782012), 109 .

Chamberlin, S., \& Marra, J. (1992). Estimation of photosynthetic rate from measurements of natural fluorescence: Analysis of the effects of light and temperature. Deep Sea Research Part A. Oceanographic Research Papers, 39, 1695-1706.

Chamberlin, W., Booth, C., Kieffer, D., Morrow, J., \& Murphy, R. C. (1990). Evidence for a simple relationship between natural fluorescence, photosynthesis and chlorophyll in the sea. Deep Sea Research Part A. Oceanographic Research Papers, 37, 951-973. 
Dall'Olmo, G., \& Gitelson, A. A. (2005). Effect of bio-optical parameter variability on the remote estimation of chlorophyll-a concentration in turbid productive waters: experimental results. Applied optics, $44,412$.

Dall'Olmo, G., \& Gitelson, A. A. (2006). Effect of bio-optical parameter variability and uncertainties in reflectance measurements on the remote estimation of chlorophyll-a concentration in turbid productive waters: modeling results. Applied optics, 45, 3577-3592.

Dekker, A. G., Vos, R., \& Peters, S. (2002). Analytical algorithms for lake water tsm estimation for retrospective analyses of tm and spot sensor data. International Journal of Remote Sensing, 23, 15-35.

Doerffer, R., \& Schiller, H. (2007). The MERIS case 2 water algorithm. International Journal Of Remote Sensing, 28, 517-535.

Doerffer, R., \& Schiller, H. (2008). MERIS Regional Coastal and Lake Case 2 Water Project. Atmospheric Correction ATBD, (pp. 1-42).

Doxaran, D., Froidefond, J.-M., \& Castaing, P. (2003). Remote-sensing reflectance of turbid sediment-dominated waters. reduction of sediment type variations and changing illumination conditions effects by use of reflectance ratios. Applied Optics, 42, 2623-2634.

Duan, H., Ma, R., Zhang, Y., Loiselle, S. A., Xu, J., Zhao, C., Zhou, L., \& Shang, L. (2010). A new three-band algorithm for estimating chlorophyll concentrations in turbid inland lakes. Environmental Research Letters, 5, 044009 .

Falkowski, P., \& Kolber, Z. (1995). Variations in chlorophyll fluorescence yields in phytoplankton in the world oceans. Functional Plant Biology, 22, 341-355. 
Falkowski, P. G., \& Raven, J. A. (2013). Aquatic photosynthesis. Princeton University Press.

Gilerson, A., Zhou, J., Hlaing, S., Ioannou, I., Schalles, J., Gross, B., Moshary, F., \& Ahmed, S. (2007). Fluorescence component in the reflectance spectra from coastal waters. Dependence on water composition. Optics Express, 15, $15702-15721$.

Gilerson, A. A., Gitelson, A. A., Zhou, J., Gurlin, D., Moses, W., Ioannou, I., \& Ahmed, S. A. (2010). Algorithms for remote estimation of chlorophyll-a in coastal and inland waters using red and near infrared bands. Optics Express, 18, 24109-24125.

Gitelson, A. (1992). The peak near $700 \mathrm{~nm}$ on radiance spectra of algae and water: relationships of its magnitude and position with chlorophyll concentration. International Journal Of Remote Sensing, 13, 3367-3373.

Gitelson, A. A., Gurlin, D., Moses, W. J., \& Barrow, T. (2009). A bio-optical algorithm for the remote estimation of the chlorophyll-a concentration in case 2 waters. Environmental Research Letters, 4, 045003.

Gons, H. J. (2005). Effect of a waveband shift on chlorophyll retrieval from MERIS imagery of inland and coastal waters. Journal Of Plankton Research, 27, 125-127.

Gons, H. J., Auer, M. T., \& Effler, S. W. (2008). MERIS satellite chlorophyll mapping of oligotrophic and eutrophic waters in the Laurentian Great Lakes. Remote Sensing of Environment, 112, 4098-4106.

Gower, J., Doerffer, R., \& Borstad, G. A. (1999). Interpretation of the $685 \mathrm{~nm}$ peak in water-leaving radiance spectra in terms of fluorescence, absorption 
and scattering, and its observation by MERIS. International Journal Of Remote Sensing, 20, 1771-1786.

Gower, J., Hu, C., Borstad, G., \& King, S. (2006). Ocean Color Satellites Show Extensive Lines of Floating Sargassum in the Gulf of Mexico. Geoscience and Remote Sensing, IEEE Transactions on, 44, 3619-3625.

Gower, J., \& King, S. (2007). Validation of chlorophyll fluorescence derived from MERIS on the west coast of Canada. International Journal Of Remote Sensing, 28, 625-635.

Gower, J., King, S., Borstad, G., \& Brown, L. (2005). Detection of intense plankton blooms using the $709 \mathrm{~nm}$ band of the MERIS imaging spectrometer. International Journal Of Remote Sensing, 26, 2005-2012.

Gower, J., King, S., \& Goncalves, P. (2008). Global monitoring of plankton blooms using MERIS MCI. International Journal Of Remote Sensing, 29, 6209-6216.

Gower, J., King, S., Yan, W., Borstad, G., \& Brown, L. (2003). Use of the 709 $\mathrm{nm}$ band of meris to detect intense plankton blooms and other conditions in coastal waters. In Proc. MERIS User Workshop.

Håkanson, L., \& Bryhn, A. C. (2008). Eutrophication in the Baltic Sea: present situation, nutrient transport processes, remedial strategies. Springer-Verlag Berlin Heidelberg.

Hällfors, H., Hajdu, S., Kuosa, H., \& Larsson, U. (2011). Vertical and temporal distribution of the dinoflagellates Dinophysis acuminata and D. norvegica in the Baltic Sea. Boreal Environment Research, 16, 121-135.

Härmä, P., Vepsäläinen, J., Hannonen, T., Pyhälahti, T., Kämäri, J., Kallio, K., Eloheimo, K., \& Koponen, S. (2001). Detection of water quality using 
simulated satellite data and semi-empirical algorithms in finland. Science of the Total Environment, 268, 107-121.

HELCOM (2003). The Baltic Marine Environment 1999-2002. Baltic Sea Environment Proceedings No. 87, (pp. 1-48).

HELCOM (2005). General guidelines on quality assurance for monitoring in the Baltic Sea. Manual for Marine Monitoring in the COMBINE Programme of HELCOM, (pp. 21-198).

HELCOM (2006). Development of tools for assessment of eutrophication in the Baltic Sea. Baltic Sea Environment Proceedings No. 104, (pp. 1-64).

Hoge, F. E., Lyon, P. E., Swift, R. N., Yungel, J. K., Abbott, M. R., Letelier, R. M., \& Esaias, W. E. (2003). Validation of Terra-MODIS phytoplankton chlorophyll fluorescence line height. I. Initial airborne lidar results. Applied optics, 42, 2767-2771.

$\mathrm{Hu}$, C. (2009). A novel ocean color index to detect floating algae in the global oceans. Remote Sensing of Environment, 113, 2118-2129.

Hu, C., \& Feng, L. (2017). Modified MODIS fluorescence line height data product to improve image interpretation for red tide monitoring in the eastern Gulf of Mexico. Journal of Applied Remote Sensing, 11, 012003.

Hu, C., Feng, L., Lee, Z., Davis, C. O., Mannino, A., McClain, C. R., \& Franz, B. A. (2012). Dynamic range and sensitivity requirements of satellite ocean color sensors: learning from the past. Applied optics, 51, 6045-6062.

Hu, C., Lee, Z., Ma, R., Yu, K., Li, D., \& Shang, S. (2010). Moderate Resolution Imaging Spectroradiometer (MODIS) observations of cyanobacteria blooms in Taihu Lake, China. Journal Of Geophysical Research-Oceans, 115, C04002. 
Hu, C. M., Carder, K. L., \& Muller-Karger, F. E. (2001). How precise are SeaWiFS ocean color estimates? Implications of digitization-noise errors. Remote Sensing of Environment, 76, 239-249.

Hu, C. M., Muller-Karger, F. E., Taylor, C., Carder, K. L., Kelble, C., Johns, E., \& Heil, C. A. (2005). Red tide detection and tracing using MODIS fluorescence data: A regional example in SW Florida coastal waters. Remote Sensing of Environment, 97, 311-321.

Hunter, P. D., Tyler, A. N., Carvalho, L., Codd, G. A., \& Maberly, S. C. (2010). Hyperspectral remote sensing of cyanobacterial pigments as indicators for cell populations and toxins in eutrophic lakes. Remote Sensing of Environment, $114,2705-2718$.

Kahru, M., Savchuk, O. P., \& Elmgren, R. (2007). Satellite measurements of cyanobacterial bloom frequency in the Baltic Sea: interannual and spatial variability. Marine Ecology Progress Series, 343, 15-23.

Karlson, B., Edler, L., Granéli, W., Sahlsten, E., \& Kuylenstierna, M. (1996). Subsurface chlorophyll maxima in the Skagerrak-processes and plankton community structure. Journal Of Sea Research, 35, 139-158.

Kiefer, D. A., \& Reynolds, R. A. (1992). Advances in understanding phytoplankton fluorescence and photosynthesis. In Primary productivity and biogeochemical cycles in the sea (pp. 155-174). Springer.

Kowalczuk, P., A Stedmon, C., \& Markager, S. (2006). Modeling absorption by $\mathrm{CDOM}$ in the Baltic Sea from season, salinity and chlorophyll. Marine Chemistry, 101, 1-11.

Kowalczuk, P., Stoń-Egiert, J., Cooper, W. J., Whitehead, R. F., \& Durako, M. J. (2005). Characterization of chromophoric dissolved organic matter 
(CDOM) in the Baltic Sea by excitation emission matrix fluorescence spectroscopy. Marine Chemistry, 96, 273-292.

Kratzer, S., Brockmann, C., \& Moore, G. (2008). Using MERIS full resolution data to monitor coastal waters — A case study from Himmerfjärden, a fjordlike bay in the northwestern Baltic Sea. Remote Sensing of Environment, 112, 2284-2300.

Kutser, T. (2004). Quantitative detection of chlorophyll in cyanobacterial blooms by satellite remote sensing. Limnology And Oceanography, 49, 21792189.

Kutser, T. (2009). Passive optical remote sensing of cyanobacteria and other intense phytoplankton blooms in coastal and inland waters. International Journal Of Remote Sensing, 30, 4401-4425.

Kutser, T., Metsamaa, L., Strombeck, N., \& Vahtmae, E. (2006). Monitoring cyanobacterial blooms by satellite remote sensing. Estuarine Coastal And Shelf Science, 67, 303-312.

Kutser, T., Paavel, B., Verpoorter, C., Ligi, M., Soomets, T., Toming, K., \& Casal, G. (2016). Remote Sensing of Black Lakes and Using $810 \mathrm{~nm}$ Reflectance Peak for Retrieving Water Quality Parameters of Optically Complex Waters. Remote Sensing, 8, 497-15.

Le, C., Hu, C., English, D., Cannizzaro, J., \& Kovach, C. (2013). Climate-driven chlorophyll-a changes in a turbid estuary: Observations from satellites and implications for management. Remote Sensing of Environment, 130, 11-24.

Letelier, R. M., \& Abbott, M. R. (1996). An analysis of chlorophyll fluorescence algorithms for the moderate resolution imaging spectrometer (MODIS). Remote Sensing of Environment, 58, 215-223. 
Martin, A. J. (2004). MODIS Detects a Devastating Algal Bloom in Paracas Bay, Peru. Journal of Geophysical Research, 109, B10208.

Matthews, M. W., Bernard, S., \& Robertson, L. (2012). An algorithm for detecting trophic status (chlorophyll-a), cyanobacterial-dominance, surface scums and floating vegetation in inland and coastal waters. Remote Sensing of Environment, 124, 637-652.

McKee, D., Cunningham, A., Wright, D., \& Hay, L. (2007). Potential impacts of nonalgal materials on water-leaving Sun induced chlorophyll fluorescence signals in coastal waters. Applied optics, 46, 7720-7729.

Metsamaa, L., Kutser, T., \& Strombeck, N. (2006). Recognising cyanobacterial blooms based on their optical signature: a modelling study. Boreal Environment Research, 11, 493-506.

Moses, W. J., Gitelson, A. A., Berdnikov, S., \& Povazhnyy, V. (2009). Estimation of chlorophyll- aconcentration in case II waters using MODIS and MERIS data - successes and challenges. Environmental Research Letters, 4, 045005 .

Moses, W. J., Gitelson, A. A., Berdnikov, S., Saprygin, V., \& Povazhnyi, V. (2012). Operational MERIS-based NIR-red algorithms for estimating chlorophyll-a concentrations in coastal waters - The Azov Sea case study. Remote Sensing of Environment, 121, 118-124.

Nair, A., Sathyendranath, S., Platt, T., Morales, J., Stuart, V., Forget, M.H., Devred, E., \& Bouman, H. (2008). Remote sensing of phytoplankton functional types. Remote Sensing of Environment, 112, 3366-3375.

Neville, R., \& Gower, J. (1977). Passive remote sensing of phytoplankton via chlorophyll $\alpha$ fluorescence. Journal of Geophysical Research, 82, 3487-3493. 